Luke, a year after they were married and shortly afterwards suffered a breast abscess that simply wouldn't heal. This resulted finally in an operation to lance the abscess, but by the following Easter (1938), Dorothy was in pain all over and severely restricted in her movements. She had suffered an acute attack of rheumatoid arthritis at the age of 28 and the consequences of this never left her. She was sent to the Spa at Buxton, Derbyshire, for treatment that gave her some remission, but such 'cure' as she knew was never to be permanent. For many years, Dorothy showed great courage in the face of personal physical suffering. This started for her at an age when most young women were settling into family life and not struggling, in addition, with the enormously challenging problems of an academic career, newly opened in X-ray crystallography.

The following chapter describes her very important work on penicillin during the war, the birth of their second child, Elisabeth, their second son, Toby, and her election to the Royal Society in 1947. Kathleen Lonsdale, a fellow crystallographer from University College London, was one of the first two women elected to the society just two years previously. Dorothy's election brought many congratulations from the crystallographic world and the pithy comment from Justin Waddington, "If a woman FRS can have three children, anyone might do anything".

The next chapters relate the details and personal stories surrounding the study and solutions of the structures of vitamin $\mathrm{B}_{12}$ and insulin. It was during this period that the electronic computer made a vital appearance in X-ray crystallography. It was to revolutionize the field and in particular to speed up the very tedious manual calculations previously made by Dorothy using the famous Beevers-Lipson strips, a brilliant innovation from Arnold Beevers and Henry Lipson, two UK crystallographers based in Bragg's laboratory in Manchester. It was for her out- standing work on vitamin $\mathrm{B}_{12}$ and "other important molecules of biological significance" that Dorothy was awarded the Nobel prize for chemistry in 1964. She received the wonderful news in Ghana, where she was staying with Thomas at the time. He had been appointed in 1961 as the first director of the new Institute of African Studies at the University of Ghana and Dorothy tried to spend some time with him there each year. But following the military coup in 1966, Thomas returned to Oxford and a fellowship at Balliol. Soon afterwards, they moved into Crab Mill, Illmington, to the old house of Thomas's parents, where Dorothy was to spend the rest of her life. Like her parents before her, Dorothy had managed her family and marriage 'split' initially between towns in the United Kingdom and then for several years in countries abroad.

The year after receiving the Nobel prize, she was awarded the Order of Merit, the highest British honour any citizen can receive and of which there are only 24 members at any time; new members really do fill dead men's shoes. Dorothy was the first woman to receive this honour since Florence Nightingale in 1907.

Honours followed upon honours as Dorothy went on to receive many honorary degrees and scientific accolades from around the world. She became the president of the Pugwash Conferences on Science and World Affairs in the mid-1970s and campaigned tirelessly on behalf of international peace for many years. On the question of disarmament, she wrote, "I do think that Pugwash has been useful as one more way of making close contacts between leading scientists in different fields, probably in preventing worse from happening in the way of wars, probably assisting, if very imperfectly, the practice of peace". She visited Russia, China and Vietnam when it was very much more difficult for scientists to travel there, and made lifelong friends among the crystal-

\section{Bubbling bauble}

Io, the innermost of the four moons orbiting Jupiter, sports active volcanoes on its surface. It orbits so close to its parent planet that the tidal pull of Jupiter squeezes the moon rhythmically, generating heat in its interior which drives the volcanic activity. The image shown here was obtained by the Galileo space probe, and is one of many examples of space imagery to be found in Empire of the Sun: Planets and Moons of the Solar System by John Gribbin and Simon Goodwin (Constable, E15.99).

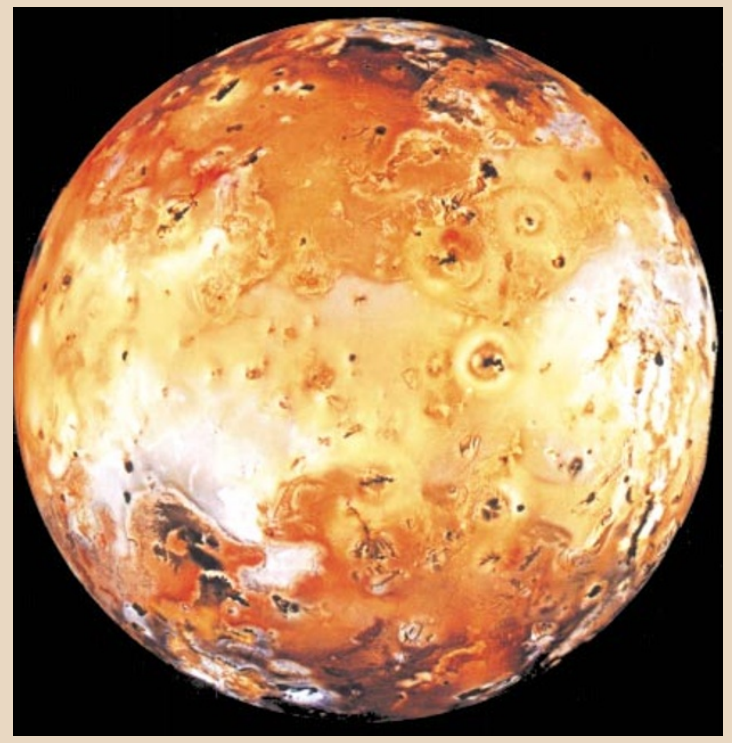

Nature ๑ Macmillan Publishers Ltd 1998 lographers in these countries.

Dorothy nominally retired from Oxford University 17 years before she died, but she continued working on the structure of insulin for many more years; she was the chancellor of Bristol University during most of this time, and continued to travel around the world for Pugwash and for other international seminars and meetings, seemingly never tiring of working with and for others, despite her increasingly frail physique, and in particular after Thomas died in 1982.

Ferry has demonstrated her very considerable talents as a science writer in this brilliant biography of Britain's most famous, yet most modest and gentle, woman of science and protagonist of peace. It is a must for all serious crystallographers as well as science historians, since it describes wonderfully well so much of our crystallographic history, both the techniques and the personalities, over a lifetime of very significant discoveries and technological developments.

Judith A. K. Howard is in the Department of

Chemistry, University of Durham, Durham

DH1 3LE, UK.

\section{Casting outthe printers đ̈levils}

\section{The Nature of the Book: Print and Knowledge in the Making}

by Adrian Johns

University of Chicago Press: 1998. 753 pp.

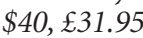

\section{Michaellunter}

Francis Bacon saw printing as one of the inventions that had "changed the appearance and state of the whole world", and ever since his time the printed book has been a potent symbol of the preservation and transmission of reliable knowledge. Indeed, the chief landmarks of the history of science are books like Copernicus's De revolutionibus (1543) or Newton's Principia (1687). Yet only a moment's reflection is required to realize that the publication of science books, as much as any other kind of book, is a complex process, involving a range of parties and interests, not all with common aims.

It is basically this insight, applied to the burgeoning scientific culture of seventeenth-century England, that underlies Adrian Johns's provocative and stimulating, if ultimately not wholly satisfactory, book. He argues that the nature of the book in seventeenth-century England was inextricably bound up with the ways in which books were printed and marketed, and that the ultimate control over what ideas were presented, and the manner in which they reached the public, had far less to do with the authors than with the producers - the printers, booksellers and others involved in the book-trade 
at the time. The result was that the dissemination of reliable data was far more problematic for scientists of the day than has generallybeen appreciated.

A striking example of this is provided by the first scientific periodical, Philosophical Transactions. Within two years of its inauguration in 1665, the run of issues was 'contaminated' by an unauthorized publication in matching format put out by the same printer; this took in at least one early reader, the diarist John Evelyn, who dutifully had the offending item bound into his set of the journal.

Equally strange is the case of John Flamsteed's Historia Coelestis, of which two distinct versions were published, one by Flamsteed himself, the other by Isaac Newton and Edmond Halley using Flamsteed's data. The latter differs from the former not least in lacking the star charts that Flamsteed considered crucial to the work. Although this episode owed more to a clash of personalities than to the normal circumstances of publishing at the time, it is nevertheless grist to Johns's mill. He revels in the instability of the printed word that such cases reveal, arguing (perhaps with some exaggeration) that Newton, Boyle and their contemporaries spent as much time negotiating how their books were printed and read as in experimenting.

By way of background, a series of detailed chapters takes us on a fascinating exploration of the world of books in early modern London, the points made being reinforced at every stage by the profuse use of well-selected illustrations. We encounter the printers, the booksellers' shops and the Stationers Company through which the trade in printed material was organized. We also learn about the procedures for censorship that existed, and the way in which they operated. Here, Johns repeatedly emphasizes how fully the producers of books were in control; indeed, the author appears in a very peripheral role, dependent on the whims of printers when consulted at all.

Yet, although Johns makes clear what a cut-throat business it was, he also illustrates the producers' awareness of the need for some form of supervision over what was printed and by whom. From the sixteenth century onwards this was achieved by a mutually advantageous arrangement between the Stationers and the prerogative powers of the Crown. But potential for conflict existed, not least in the aftermath of the Civil War, as comes out particularly through two chapters dealing with the attempt by John Streater and Richard Atkyns to use royal power to subvert the Stationers' privileges, with rival histories of printing used to support the different sides in this dispute.

This leads to perhaps the most fascinating chapter in the book, that on "the Physiology of Reading", in which Johns brings together the history of science and cultural history. Deploying the views on perception of early

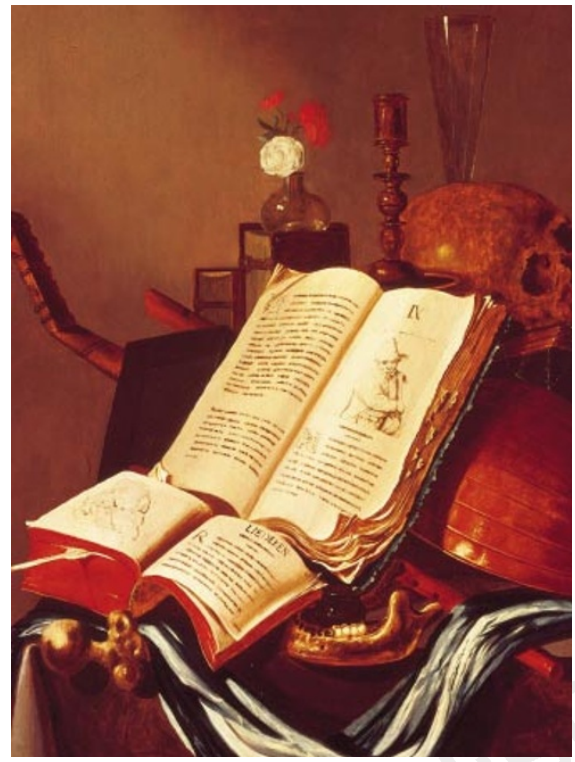

The written word conveyed in oils: painting by the Dutch seventeenth-century artist Edwaert Colyer.

modern authors like Thomas Willis, who emphasized the interconnection of vision and imagination, Johns illustrates how these resonated with contemporary theories of the 'passions', understood as impulses generated either by sensations or by internal bodily states, to produce an awareness that the encounter between the reader and the printed word was radically unstable. Only careful supervision and control could overcome this, and here, as elsewhere, Johns wants to argue for the role of trust.

This was crucial precisely because the book itself was not a self-evidently reliable commodity; readers therefore had to know how to approach any text through knowledge of its background in order to establish its trustworthiness. Moreover, he wants to argue that in an important sense this relativism of the printed word transcends the specific context of early modern practice. Responding to the argument that the invention of the steam press in the nineteenth century brought about a real revolution that had simply failed to occur earlier, he argues that, on the contrary, many of the issues of trust and credibility that he illustrates in his book are still with us, in the context not only of print but also of electronic media.

In making his case, Johns has evidently come to feel that the most effective method is through a detailed exposition of the circumstances of the production and reception of books in seventeenth-century England, and particularly through recounting key episodes at length. Certainly, this is something for which he has a real flair, with an enviable eye for telling detail, a skill in narrative and an ability to intersperse this with ingenious, often deflationary, asides. The question is whether he has allowed himself to be slightly carried away. Overall, the book is 750 pages long, while the chapters are massive — the longest runs to
129 pages - and the thread of the argument sometimes gets lost in them. Moreover, the cumulative effect is wearying: only on page 444 do we reach the chapters devoted to the Royal Society and science books.

This is the more problematic since, although detailed and informative, the book is suggestive rather than definitive. There are many aspects of the history of the book in seventeenth-century England that are not pursued here. Johns's concern is essentially about the control of the printed word, and he has virtually nothing to say about print runs and the relative popularity of different kinds of books at the time. (It is worth noting that his critique of claims for a 'print revolution' in the period focuses almost exclusively on the fixity of print rather than its ability to produce massive numbers of copies of a book in the time it took scribal copyists to produce one.)

But there are also omissions directly germane to Johns's chosen theme. The book focuses almost exclusively on London, and publishing in Oxford is mentioned only in passing: this means that there is no account of the attempts to make learned publishing viable at the Clarendon Press under the auspices of Bishop John Fell in the late seventeenth century, although these have interesting resonances with the efforts of the Royal Society in London which are dealt with at length.

Even on topics that are covered, Johns does not always have the final word. For instance, although there is an acute and interesting section on Robert Boyle, dwelling particularly on his complaints about unauthorized editions of his works at home and abroad, no attempt is made to test Boyle's statements by surveying the actual publishing history of his works. Yet this would have revealed a rather different picture, as will be documented in detail in the new edition of his works due to be published next year.

For one thing, Johns is so keen to make Boyle's experiences with 'usurpation' seem normal in the cut-throat publishing world of the time that he accepts his complaints at face value, failing to consider the possibility that they might form part of a pattern of 'protesting too much' on Boyle's part - in relation not just to booksellers and literary thieves, but also to every other aspect of his life as an author - which arguably tells us less about the actual state of affairs than about a slightly obsessive streak in Boyle with significant implications for an understanding of his intellectual personality. More importantly, Johns seems unaware that Boyle in fact adopted a rather canny publishing practice, always working with more than one bookseller at a time in an evident attempt to play them off against one another — a strategy that makes all the better sense against the rather unstable commercial background sketched here. 
Such instances could be multiplied, and the fact is that, for all its length, The Nature of the Book lacks not only definitiveness, but also balance: throughout its 750 pages it is arguing a case rather than saying the final word even on scientific publishing in seventeenth-century England.

Yet Johns's decision to write a big book rather than a smaller one may be germane to the very issues that dominate the work itself, namely the extent to which people's approach to the printed word is affected by factors extrinsic to a book's actual content. People defer to long books, and Johns may well be correct in thinking that a weighty tome like this will gain an authority for his iconoclastic view of print that would not have been the case with a work half the length. Yet, if he is right in this, it is to be hoped that he will not be a victim of his own success: readers should not be discouraged by the sheer length of the book from sampling some of the lively and insightful sections that make it up.

Michael Hunter is in the Department of History,

Birkbeck College, University of London, London WC1 7HX, UK.

\section{Roaming the landscape}

\section{Fractal River Basins: Chance and Self-Organization}

by Ignacio Rodríguez-Iturbe and Andrea Rinaldo

Cambridge University Press: 1997. 547 pp.

$£ 70, \$ 100$

\section{David R. Montgomery}

The search for meaning in the branching patterns of channel networks has seduced geomorphologists for decades, and Fractal River Basins makes a compelling case for a fundamental order in landscape form. Ignacio Rodríguez-Iturbe and Andrea Rinaldo provide a benchmark synthesis and passionate exploration of the ways in which fractal geometry can be used to analyse river networks, and how the concepts of optimal channel networks (OCNs) and self-organized criticality (SOC) can be applied to models of landscape evolution. In a rigorous and engaging style, they explore the themes of necessity and chance in river-basin evolution to develop the argument that fractal geometry contributes more to geomorphology than just a convenient shorthand for the thumbprint of river incision.

Fractal River Basins goes beyond the descriptive application of fractals to examine the universal aspects of landscape development. An excellent overview of river-basin morphology opens the book and leads into a discussion of the use of fractals to describe the wide variety of scale-free aspects of river networks and river-basin morphology.

The authors delve into examples where fractal descriptions and models are supported by observations from real networks, but they also discuss how channel networks are not simple, self-affined monofractals, and emphasize that planform models of network structure are not demanding when it comes to statistical tests of their veracity. A wide variety of models produce arborescent patterns that resemble natural channel networks, and the robust generality of the fractal aspects of channel networks has led many geomorphologists to question the utility of fractals for elucidating the processes of network growth and landscape evolution.

Rodríguez-Iturbe and Rinaldo argue that models of landscape evolution should be assessed by examining the three-dimensional structure of basins (that is, including elevation), and they propose that OCNs provide a bridge between fractal patterns and landscape-forming processes. In a discussion that summarizes a decade of cutting-edge research, they start from the premiss that channel networks are characterized by minimum rates of energy expenditure to show that the connectivity and elevation structure of OCNs resembles that of natural drainage basins.

They argue that both chance and necessity govern river-basin evolution - chance through the effect of random variations in initial conditions and necessity through minimization of the total rate of energy expenditure both for the whole network and locally throughout a river network. In drawing previous work together into a single chapter the authors provide a very welcome and valuable synthesis of a wide range of studies on OCNs and a comprehensive case for their relevance to river-basin evolution.

The authors' examination of how the structure of river basins is formed bySOC contrasts with a perception among some process geomorphologists that SOC offers little to those seeking to understand land-form. It is not too surprising, therefore, that in framing their discussion oflandscape self-organization and river-basin evolution, Rodríguez-Iturbe and Rinaldo decry the "reductionist, processoriented tenet to which most geomorphology is committed". But both reductionism and the synthetic examination of emergent properties are necessary tools for the well-rounded geomorphologist, given that process geomorphology in general seeks to understand how and to what degree the processes driving landscape evolution translate across a wide range of scales.

Moreover, some process-based understanding is necessary to evaluate the implications of the principle of minimum energy dissipation; without a tie to landscapeforming processes, the existence of broad, ubiquitous, self-similar characteristics of landscapes teaches us little about how particular landscapes evolve. Even though a fundamental tension underlies the search for universal and landscape-specific aspects of land-form, there is value in searching for insight in both the ubiquitous and the discriminating characteristics of landscapes.

However one looks at the subject, Fractal River Basins is an important book that explores the fundamental dynamics behind the generally uniform appearance of river networks and fluvially sculpted landscapes. The reader seeking an exploration of the relevance of fractal geometry to the description of river networks will be rewarded with a stateof-the-art review.

The seductive beauty of channel networks will continue to inspire investigators to examine the deep symmetry expressed in landscape form, and Fractal River Basins provides a bold synthesis of probability, physics and geometry that will stand as a definitive work on a complex subject. Geomorphologists and physicists alike will find the book thought-provoking, and I highly recommend this stimulating work as a means of focusing one's thinking on the role of fractals, OCNs and SOC in fluvial geomorphology and landscape evolution.

David R. Montgomery is in the Department of Geological Sciences, University of Washington, Seattle, Washington 98195-1310, USA.

\section{The splendour of Yellowstone}

This aerial view of Sour Creek, showing the mosaic of meandering streams, ponds and wetlands across open pasture, is one of many photographs taken by Norbert Rosing for Yellowstone (Firefly, \$24.95), in which the photographer aims to convey the fascination of Yellowstone National Park, with its enduring geological monuments, geysers, plants and wildlife.

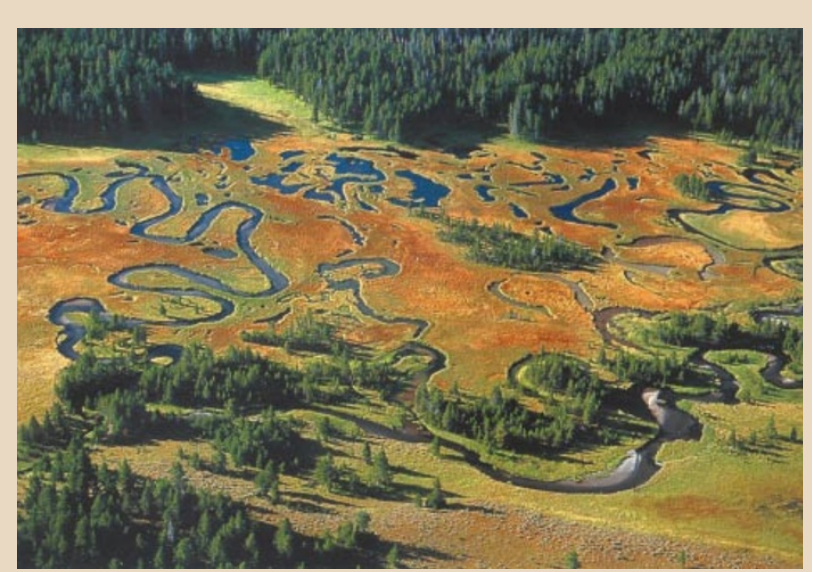

